\title{
Inferior Mesenteric Vein
}

National Cancer Institute

\section{Source}

National Cancer Institute. Inferior Mesenteric Vein. NCI Thesaurus. Code C32782.

A blood vessel running parallel to the inferior mesenteric artery that drains blood from the descending and sigmoid colon as well as the rectum into the splenic vein. 